\title{
Dificuldades Conceituais em Física Apresentadas por Alunos Ingressantes em um Curso de Engenharia
}

Conceptual Physics difficulties presented by freshmen in an engineering course

\author{
Vagner Bernal Barbeta e Issao Yamamoto \\ Departamento de Física, UNIFEI, Centro Universitário da FEI \\ Av. Humberto de A. C. Branco, 3972, 09850-901, S. B. Campo, SP, Brasil \\ vbarbeta@fei.edu.br
}

Recebido em 19 de outubro, 2001. Manuscrito revisado em 30 de julho, 2002. Aceito em 6 de agosto, 2002.

\begin{abstract}
O objetivo deste trabalho é o de apresentar alguns resultados obtidos através da aplicação de um teste entre alunos ingressantes no ciclo básico de um curso de engenharia. Este teste visou levantar as principais dificuldades conceituais em Física, apresentadas por esses alunos, no tópico de mecânica clássica. O teste aplicado foi uma adaptação do "Mechanics Baseline Test", que tem sido utilizado com esta finalidade em algumas universidades americanas. O que foi observado é que, embora os alunos tenham tido contato prévio com os tópicos explorados pelo teste, o nível de amadurecimento sobre o assunto é ainda pequeno, prevalecendo conceitos baseados em um senso comum impreciso.
\end{abstract}

In this work we show some results obtained through the application of a test among engineering freshmen. It was intended to reveal the main conceptual difficulties in classical mechanics shown by the students. The test is a version of the "Mechanics Baseline Test", which has been used in some American universities to evaluate the student background in this area. We were able to observe that although the students have a previous knowledge regarding the physics concepts explored in the test, their level of maturity in the subject is still unsatisfactory, prevailing ideas based on an imprecise common sense.

\section{Introdução}

O início de um curso de física básica para o ensino superior normalmente envolve o estudo de tópicos de mecânica de pontos materiais. Em princípio, os conceitos explorados são aqueles que já foram (ou deveriam ter sido) aprendidos no ensino médio, porém com um aprofundamento maior e com o uso de ferramentas de cálculo diferencial e integral. Esse tipo de abordagem em espiral por refinamentos sucessivos ("spiral approach"), com a reexplicação de um dado assunto com um nível de aprofundamento maior, é uma técnica usual dentro de diversas áreas de ensino [1]. Para que possa ser aplicada, no entanto, é importante que o aluno tenha tido sucesso na etapa anterior do processo.

As dificuldades enfrentadas pelos alunos no estudo de física do ensino superior são muitas vezes atribuídas à deficiência dos alunos em manipular o ferramental matemático que é normalmente exigido nestes cursos. Por essa razão, as disciplinas de física ministradas em cursos ligados à área de biomédicas, por exemplo, são às vezes concebidas de modo a se utilizar pouco ou nenhuma ferramenta de cálculo [2]. Isso fica mais evidente quando se analisam alguns livros didáticos que procu- ram discutir a física em termos conceituais, evitando ao máximo o uso de ferramentas matemáticas [3]. No entanto, no ensino de física para alunos das áreas de ciências exatas, a habilidade para expressar matematicamente os conceitos físicos é tão importante quanto o conhecimento dos conceitos em si. Tradicionalmente nesses cursos, a disciplina de "Cálculo" é oferecida em paralelo à disciplina de "Física", e por isso, muitas vezes o desconhecimento do cálculo é considerado o culpado pelo fracasso de parte dos alunos em obter promoção nas disciplinas de física. Deve-se atentar para o fato, porém, de que, além das ferramentas de cálculo, para que o aluno tenha sucesso em um curso de física no ensino superior, é preciso que ele domine os conceitos básicos que são explorados pela disciplina, bem como possua a habilidade para interpretar e criar gráficos.

Alguns trabalhos $[4,5]$ dão uma indicação de que a interpretação de gráficos por parte dos alunos ingressantes no ensino superior é deficiente. Isso é bastante problemático, pois o uso de gráficos na explicação de conceitos de física constitui-se em uma praxe, tornandose uma linguagem especial utilizada pelo professor, e que pode não ser dominada por uma parcela dos estudantes, gerando-se assim um sério problema de comu- 
nicação.

Quanto ao conhecimento dos conceitos básicos de física, percebe-se que também não são dominados de forma satisfatória e podem, portanto, contribuir para uma maior dificuldade na obtenção de sucesso nessa disciplina de física. Em grande parte, essas dificuldades se caracterizam pela existência de concepções alternativas, ou espontâneas, diferentes daquelas aceitas cientificamente. Essas concepções espontâneas têm sido objeto de estudo de pesquisadores de ensino de física no Brasil desde a década de 80 [6, 7]. A importância do seu estudo está no fato de que a presença de tais concepções influencia, de maneira importante, na forma pela qual os alunos aprendem os novos conceitos que lhe são ensinados. A persistência destas noções espontâneas, mesmo após anos de educação formal, indica a possibilidade de se poder criar uma superposição entre os conceitos científicos e aqueles espontâneos, tendo-se aí um obstáculo para um aprendizado significativo da física. A escolha do esquema científico ou do espontâneo se dá aparentemente pelo tipo de problema que se está analisando. Isto é, quando o problema envolve muitos conceitos formais, o esquema formal é utilizado, e quando envolve elementos do dia-a-dia, o esquema espontâneo é escolhido [8]. Em um trabalho recente [9], as concepções espontâneas têm sido identificadas como uma das barreiras para a construção de modelos mentais para a resolução de problemas de física.

Este trabalho visou identificar o grau de entendimento conceitual dos vários tópicos relativos à cinemática e à dinâmica de pontos materiais, bem como a habilidade do aluno em interpretar gráficos. Procurouse, ainda, verificar até que ponto a falta de ferramental matemático é um obstáculo para um bom aprendizado de física básica no nível superior. Para tanto, utilizouse como instrumento de pesquisa um teste, que foi aplicado entre os estudantes ingressantes em um curso de engenharia. Ele evita a necessidade de o aluno possuir conhecimentos mais aprofundados de matemática para a solução dos problemas, bastando o conhecimento de álgebra elementar. O teste é uma adaptação do " $\mathrm{Me}$ chanics Baseline Test" (MBT), que tem sido utilizado em pesquisas similares realizadas nos Estados Unidos [10].

\section{Mechanics Baseline Test (MBT)}

A fim de avaliar qualitativamente a compreensão da maioria dos conceitos fundamentais na mecânica, Hestenes e Wells elaboraram o "Mechanics Baseline Test" (MBT) [10], um conjunto de questões abrangendo conceitos de física introdutória. Os dois autores, juntamente com Swackhamer, já haviam elaborado outro teste, o "Force Concept Inventory" [11], destinado a estudantes mesmo sem treinamento formal em mecânica ou cujo conhecimento do mundo físico baseava-se no seu senso comum e na experiência pessoal. O "Mechanics Baseline Test", por seu lado, utiliza questões que não poderiam ser respondidas sem um conhecimento dos conceitos básicos de mecânica. Os dois testes se complementam, dando um bom perfil sobre o entendimento da maioria dos conceitos básicos newtonianos. $\mathrm{O}$ MBT foi escolhido pois, em princípio, o aluno ingressante no ensino superior já teve contato com os conceitos da mecânica newtoniana no ensino médio. Através da aplicação do teste, poderia ser verificado se realmente esses conceitos são dominados de forma satisfatória pelos alunos.

O teste constitui-se de 26 questões de múltipla escolha, das quais apenas 7 exigem a realização de algum tipo de cálculo matemático (estas questões envolvem basicamente conhecimentos de álgebra elementar). Portanto, as questões têm por objetivo verificar a bagagem conceitual dos alunos em física, dispensando o conhecimento de um ferramental matemático elaborado.

Na Tabela I apresenta-se a distribuição das questões, feita pelos autores do MBT, segundo os conceitos envolvidos. As questões entre parênteses indicam que outros conceitos são significativamente explorados para a solução do problema. Anexo, temos o conjunto completo das questões que compõem o MBT.

\begin{tabular}{|c|c|}
\hline Assunto & Questão \\
\hline Cinemática & \\
\hline Movimento linear & $1,(2),(3)$ \\
\hline aceleração constante & $(18), 23$ \\
\hline aceleração média & 25 \\
\hline velocidade média & 24 \\
\hline deslocamento por integração & 4 \\
\hline Movimento curvilíneo & $5,(8),(12)$ \\
\hline aceleração tangencial & $(9),(12)$ \\
\hline aceleração normal & $(2)$ \\
\hline uso da expressão $\mathrm{a}_{\mathrm{n}}=\mathrm{v}^{2} / \mathrm{r}$ & 17,21 \\
\hline Princípios Gerais (Dinâmica) & $(12),(13), 14$ \\
\hline Primeira Lei & $7,(5),(13), 19$ \\
\hline Segunda Lei & 20 \\
\hline dependência com a massa & 10,11 \\
\hline Terceira Lei & 16,22 \\
\hline Princípio da Superposição & 15 \\
\hline Trabalho-energia & $(9), 26$ \\
\hline Conservação da energia & \\
\hline Impulso-momento linear & \\
\hline Conservação do momento linear & \\
\hline Forças Específicas & \\
\hline Queda livre gravitacional & $(12),(18)$ \\
\hline Atrito & \\
\hline
\end{tabular}

Tabela I. Conceitos newtonianos do "Mechanics Baseline Test". Cada conceito é explorado na questão indicada. Os números entre parênteses indicam que outros conceitos são significativamente explorados na questão. 


\section{Amostragem e coleta de da- dos}

O teste foi aplicado, inicialmente, no segundo semestre de 1999, atingindo um total de 771 alunos matriculados em Física I, sendo 494 do diurno e 277 do noturno. No segundo semestre de 2000, o teste foi novamente aplicado, sendo pesquisados desta vez 814 alunos, 520 do diurno e 294 do noturno. O curso analisado é dividido em períodos semestrais, sendo as disciplinas de física desenvolvidas em quatro semestres, iniciando-se no $1^{\circ}$ período para os alunos do diurno, e no $2^{\circ}$ período para os alunos do noturno. Pelo fato de o curso ser semestral, há turmas que iniciam o curso tanto no primeiro quanto no segundo semestre do ano. Nos totais apresentados estão incluídos calouros bem como alunos dependentes em Física I (que não conseguiram aprovação e que foram considerados como alunos ingressantes), abrangendo-se alunos dos cursos diurno e noturno.

O teste foi aplicado nas primeiras semanas de aula.

\begin{tabular}{|c|c|c|c|c|c|c|}
\hline \multicolumn{7}{|c|}{ Agosto de 1999} \\
\hline & a & b & c & d & e & f \\
\hline q.1 & 32 & $\mathbf{6 0}$ & 3 & 2,3 & 0,8 & 2,7 \\
\hline q.2 & 5,8 & 11 & 13 & $\mathbf{4 4}$ & 18 & 8,9 \\
\hline q.3 & 8,2 & 11 & 11 & 31 & $\mathbf{1 8}$ & 20 \\
\hline q.4 & 1,2 & 4 & $\mathbf{7 6}$ & 14 & 2,9 & 1,2 \\
\hline q.5 & $\mathbf{2 , 3}$ & 51 & 14 & 4,3 & 26 & 1,7 \\
\hline q.6 & 2,3 & 35 & $\mathbf{3 2}$ & 6,9 & 18 & 5,3 \\
\hline q.7 & 2,9 & 3,8 & $\mathbf{1 5}$ & 66 & 6,1 & 5,7 \\
\hline q.8 & 11 & 21 & 26 & $\mathbf{1 3}$ & 13 & 15 \\
\hline q.9 & 3,1 & 12 & 8,6 & $\mathbf{1 0}$ & 6,9 & 58 \\
\hline q.10 & 63 & 3,5 & 7,1 & 9,3 & $\mathbf{1 5}$ & 2,3 \\
\hline q.11 & 15 & $\mathbf{1 4}$ & 8,4 & 12 & 7 & 43 \\
\hline q.12 & 22 & 12 & $\mathbf{3 , 5}$ & 3 & 16 & 43 \\
\hline q.13 & 17 & $\mathbf{2 1}$ & 9,5 & 30 & 3,6 & 18 \\
\hline q.14 & 17 & $\mathbf{4 5}$ & 4,4 & 13 & 1,7 & 18 \\
\hline q.15 & 15 & 7 & 6,1 & 16 & $\mathbf{3 2}$ & 22 \\
\hline q.16 & $\mathbf{2 5}$ & 44 & 3,5 & 3,9 & 12 & 11 \\
\hline q.17 & 1,7 & 2,5 & 51 & $\mathbf{2 8}$ & 5,1 & 11 \\
\hline q.18 & 10 & $\mathbf{1 0}$ & 12 & 11 & 12 & 43 \\
\hline q.19 & 7,1 & 33 & $\mathbf{2 2}$ & 12 & 11 & 13 \\
\hline q.20 & 23 & 37 & $\mathbf{1 9}$ & 5,7 & 1 & 13 \\
\hline q.21 & $\mathbf{6 4}$ & 7,9 & 15 & 4,7 & 0,6 & 5,7 \\
\hline q.22 & 25 & $\mathbf{2 2}$ & 28 & 5,7 & 2,2 & 16 \\
\hline q.23 & 9,7 & 17 & 17 & $\mathbf{3 3}$ & 10 & 12 \\
\hline q.24 & $\mathbf{1 9}$ & 12 & 17 & 5,7 & 26 & 18 \\
\hline q.25 & $\mathbf{1 7}$ & 22 & 11 & 10 & 17 & 21 \\
\hline q.26 & 7,3 & 8,3 & 17 & 42 & $\mathbf{6}$ & 18 \\
\hline
\end{tabular}

Foi solicitado aos alunos que respondessem a todas as questões, e optamos pela inclusão de um item "Não sei responder" (alternativa "f"), a fim de podermos ter uma idéia dos assuntos que o aluno não tivesse tido contato durante o ensino médio. Não foi permitido o uso de calculadora, já que os eventuais cálculos envolviam apenas conhecimentos de álgebra elementar. Durante a aplicação do teste, foi extensivamente divulgado que o resultado não traria qualquer benefício ou prejuízo ao aluno na obtenção da promoção na disciplina, sendo que a participação no teste foi opcional.

\section{Resultados}

Na Tabela II, tem-se o resultado dos questionários aplicados nos anos de 1999 e 2000. Nessa tabela podem-se observar os índices percentuais para cada alternativa escolhida, destacando-se em negrito os índices correspondentes às alternativas corretas.

\begin{tabular}{|c|c|c|c|c|c|c|}
\hline \multicolumn{7}{|c|}{ Agosto de 2000} \\
\hline & a & b & c & d & e & f \\
\hline q.1 & 26 & $\mathbf{6 6}$ & 2,3 & 1,2 & 1,2 & 3,2 \\
\hline q.2 & 6,9 & 8,8 & 12 & $\mathbf{4 5}$ & 17 & 10 \\
\hline q.3 & 6,1 & 13 & 8,4 & 29 & $\mathbf{1 9}$ & 24 \\
\hline q.4 & 0,7 & 2,9 & $\mathbf{7 6}$ & 14 & 4,1 & 2,5 \\
\hline q.5 & $\mathbf{3 , 4}$ & 47 & 14 & 4,5 & 26 & 4,5 \\
\hline q.6 & 2 & 29 & $\mathbf{3 9}$ & 5 & 18 & 6,6 \\
\hline q.7 & 2 & 3,7 & $\mathbf{1 4}$ & 65 & 5,3 & 9,5 \\
\hline q.8 & 7,1 & 17 & 27 & $\mathbf{1 0}$ & 14 & 25 \\
\hline q.9 & 1,8 & 6,9 & 2,8 & $\mathbf{6 , 4}$ & 6,3 & 75 \\
\hline q.10 & 62 & 2,3 & 8,2 & 7,9 & $\mathbf{1 4}$ & 4,9 \\
\hline q.11 & 13 & $\mathbf{9 , 6}$ & 5 & 9,6 & 4,3 & 58 \\
\hline q.12 & 17 & 7,5 & $\mathbf{2 , 8}$ & 1,8 & 8,1 & 62 \\
\hline q.13 & 17 & $\mathbf{2 0}$ & 6,3 & 25 & 2,3 & 29 \\
\hline q.14 & 17 & $\mathbf{4 0}$ & 1,8 & 12 & 1,2 & 27 \\
\hline q.15 & 15 & 5,5 & 5 & 14 & $\mathbf{3 0}$ & 30 \\
\hline q.16 & $\mathbf{2 3}$ & 45 & 3,8 & 2,8 & 12 & 12 \\
\hline q.17 & 0,5 & 2,2 & 46 & $\mathbf{2 6}$ & 4,3 & 20 \\
\hline q.18 & 11 & $\mathbf{6 , 8}$ & 8,4 & 8,1 & 6,8 & 59 \\
\hline q.19 & 6,1 & 33 & $\mathbf{2 6}$ & 13 & 7,9 & 14 \\
\hline q.20 & 22 & 39 & $\mathbf{1 5}$ & 5,3 & 1 & 17 \\
\hline q.21 & $\mathbf{6 4}$ & 9,2 & 15 & 3,1 & 0,9 & 6,6 \\
\hline q.22 & 23 & $\mathbf{2 5}$ & 23 & 3,9 & 0,9 & 23 \\
\hline q.23 & 9,8 & 13 & 17 & $\mathbf{2 4}$ & 9,7 & 26 \\
\hline q.24 & $\mathbf{2 0}$ & 10 & 13 & 5,8 & 24 & 28 \\
\hline q.25 & $\mathbf{1 6}$ & 16 & 11 & 8,1 & 15 & 33 \\
\hline q.26 & 9 & 6,1 & 15 & 42 & $\mathbf{6}$ & 21 \\
\hline & & & & \\
\hline
\end{tabular}

Tabela II. Percentagens das alternativas escolhidas pelos alunos (agosto de 1999 e agosto de 2000) para cada uma das questões. Em negrito destacam-se as alternativas corretas. 
Na Tabela III apresentam-se os índices percentuais de acerto obtidos pelos alunos no segundo semestre de 1999 (2s1999) e no segundo semestre de 2000 (2s2000), para as várias questões do teste. A título de comparação, transcreveram-se também os resultados obtidos pelos autores do MBT [10] em um colégio do Estado do Arizona e na Universidade de Harvard, nos Estados Unidos. Na coluna mais à direita, observa-se também o escore reduzido ou "escore z", calculado para comparação das duas turmas analisadas, para cada uma das questões. Esse parâmetro é utilizado em análises es- tatísticas para a verificação da existência ou não de diferença significativa entre 2 conjuntos de amostras [12]. Foi calculado também o escore $\mathrm{z}$ para a comparação das médias gerais de acertos entre as duas turmas analisadas, bem como para a comparação entre as turmas do segundo semestre de 1999 e as turmas do Colegial Arizona e de Harvard. Ainda nesta tabela, "N" se refere ao número de alunos analisados e "D.P." é o desviopadrão. As Figuras 1 e 2 fornecem uma comparação visual dos dados contidos na Tabela III.

\begin{tabular}{|c|c|c|c|c|c|}
\hline Questão & $\begin{array}{c}\text { Brasil } \\
\text { 2s1999 }\end{array}$ & $\begin{array}{c}\text { Brasil } \\
2 s 2000\end{array}$ & $\begin{array}{l}\text { Colegial } \\
\text { Arizona }\end{array}$ & $\begin{array}{c}\text { Univ. } \\
\text { Harvard }\end{array}$ & $\begin{array}{c}\text { Escore } \\
\mathrm{z}\end{array}$ \\
\hline 1 & 60 & 66 & 54 & 78 & $-2,47$ \\
\hline 2 & 44 & 45 & 40 & 78 & $-0,40$ \\
\hline 3 & 18 & 19 & 29 & 93 & $-0,51$ \\
\hline 4 & 76 & 76 & 85 & 67 & 0,00 \\
\hline 5 & 2 & 3 & 1 & 18 & $-1,27$ \\
\hline 6 & 32 & 39 & 45 & 87 & $-2,91$ \\
\hline 7 & 15 & 14 & 8 & 36 & 0,56 \\
\hline 8 & 13 & 10 & 23 & 81 & 1,87 \\
\hline 9 & 10 & 6 & 21 & 68 & 2,94 \\
\hline 10 & 15 & 14 & 35 & 89 & 0,56 \\
\hline 11 & 14 & 10 & 25 & 85 & 2,45 \\
\hline 12 & 4 & 3 & 12 & 24 & 1,08 \\
\hline 13 & 21 & 20 & 31 & 79 & 0,49 \\
\hline 14 & 45 & 40 & 51 & 87 & 2,01 \\
\hline 15 & 32 & 30 & 48 & 83 & 0,86 \\
\hline 16 & 25 & 23 & 16 & 60 & 0,93 \\
\hline 17 & 28 & 26 & 26 & 81 & 0,90 \\
\hline 18 & 10 & 7 & 15 & 32 & 2,14 \\
\hline 19 & 22 & 26 & 16 & 78 & $-1,86$ \\
\hline 20 & 19 & 16 & 25 & 46 & 1,57 \\
\hline 21 & 64 & 62 & 62 & 89 & 0,82 \\
\hline 22 & 22 & 26 & 56 & 32 & $-1,86$ \\
\hline 23 & 33 & 25 & 28 & 84 & 3,51 \\
\hline 24 & 19 & 21 & 29 & 59 & $-0,99$ \\
\hline 25 & 17 & 16 & 25 & 61 & 0,54 \\
\hline 26 & 6 & 8 & 13 & 53 & 1,56 \\
\hline $\mathrm{N}$ & 771 & 814 & 600 & 183 & \\
\hline Média (\%) & 26 & 25 & 32 & 66 & \\
\hline D.P. (\%) & 11 & 11 & 11 & 14 & \\
\hline
\end{tabular}

Tabela III. Resultados percentuais obtidos na aplicação do "Mechanics Baseline Test" em uma escola de engenharia do Brasil, num colégio do Arizona e na Universidade de Harvard. 


\section{Discussão e análise}

\section{V.1. Análise dos resultados dos testes}

Analisando-se visualmente as Figuras 1 e 2, não se notam grandes diferenças entre os resultados obtidos entre os alunos que ingressaram no primeiro período em agosto de 1999 e os que ingressaram em agosto de 2000 , tanto nas questões consideradas mais fáceis, isto é, aquelas com maiores índices de acertos $(4,21$ e 1), quanto nas mais difíceis, isto é, aquelas com menores índices de acertos (5, 12 e 26). Ao calcular-se o escore reduzido, ou escore $z$, para a comparação entre a média de acertos das duas turmas analisadas (a de agosto de 1999 e a de agosto de 2000), obtém-se um valor de $\mathrm{z}=1,81$, o que indica que as diferenças entre as turmas não são significativas a um nível de significância de 0,05. Fazendo-se uma análise semelhante entre a turma de agosto de 1999 e a do colégio no Arizona, obtém-se um valor de $\mathrm{z}=-10,02$, o que permite concluir que existe uma diferença significativa entre os dois grupos de alunos. Para o caso da comparação com os alunos de Harvard, obtém-se um valor de $\mathrm{z}=-36,10$, indicando que estes apresentam diferenças significativas com os alunos brasileiros, sendo os alunos de Harvard significativamente mais bem preparados. Para os alunos de Harvard, as questões mais fáceis foram a 3, 10 e 21, e as mais difíceis a 5, 12 e 18 .

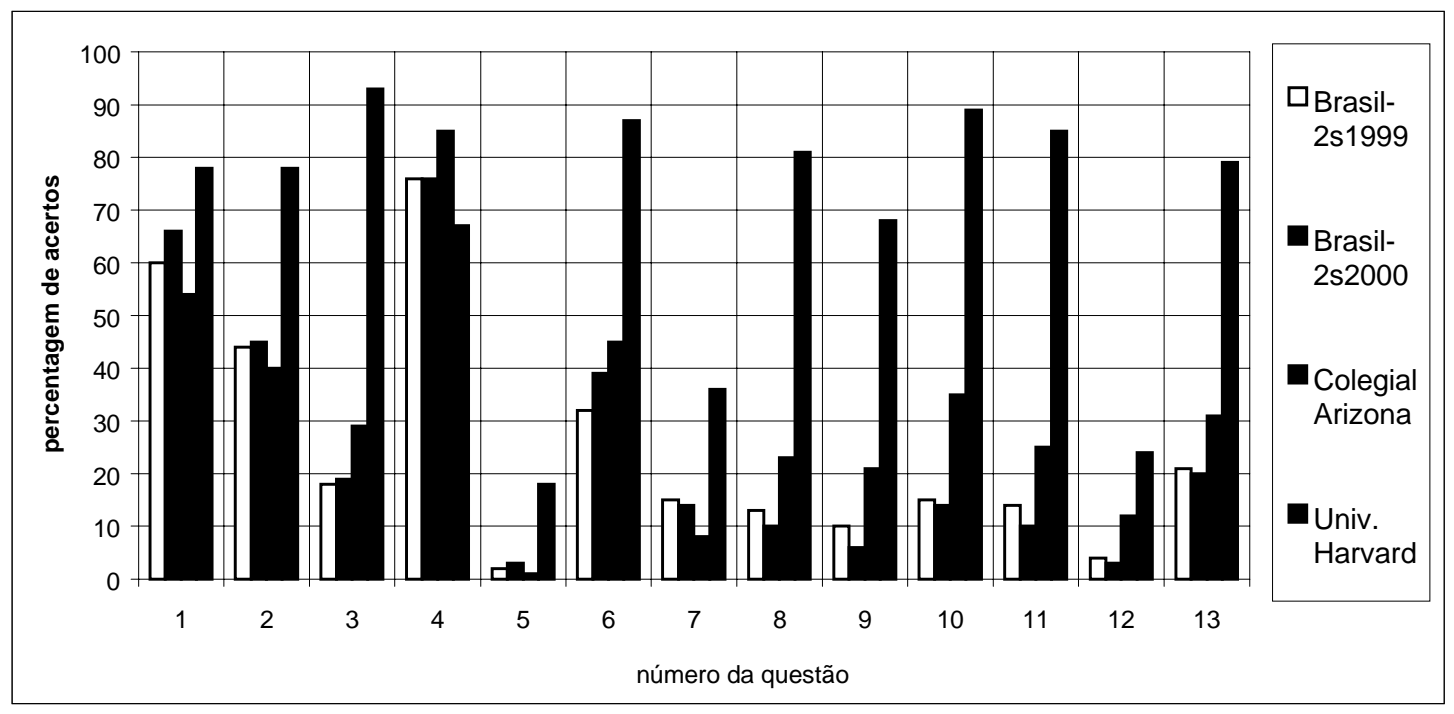

Figura 1. Resultados percentuais (questôes 1 a 13) obtidos na aplicação do Mechanics Baseline Test (agosto de 1999 e agosto de 2000), num colégio do Arizona e na Universidade de Harvard.

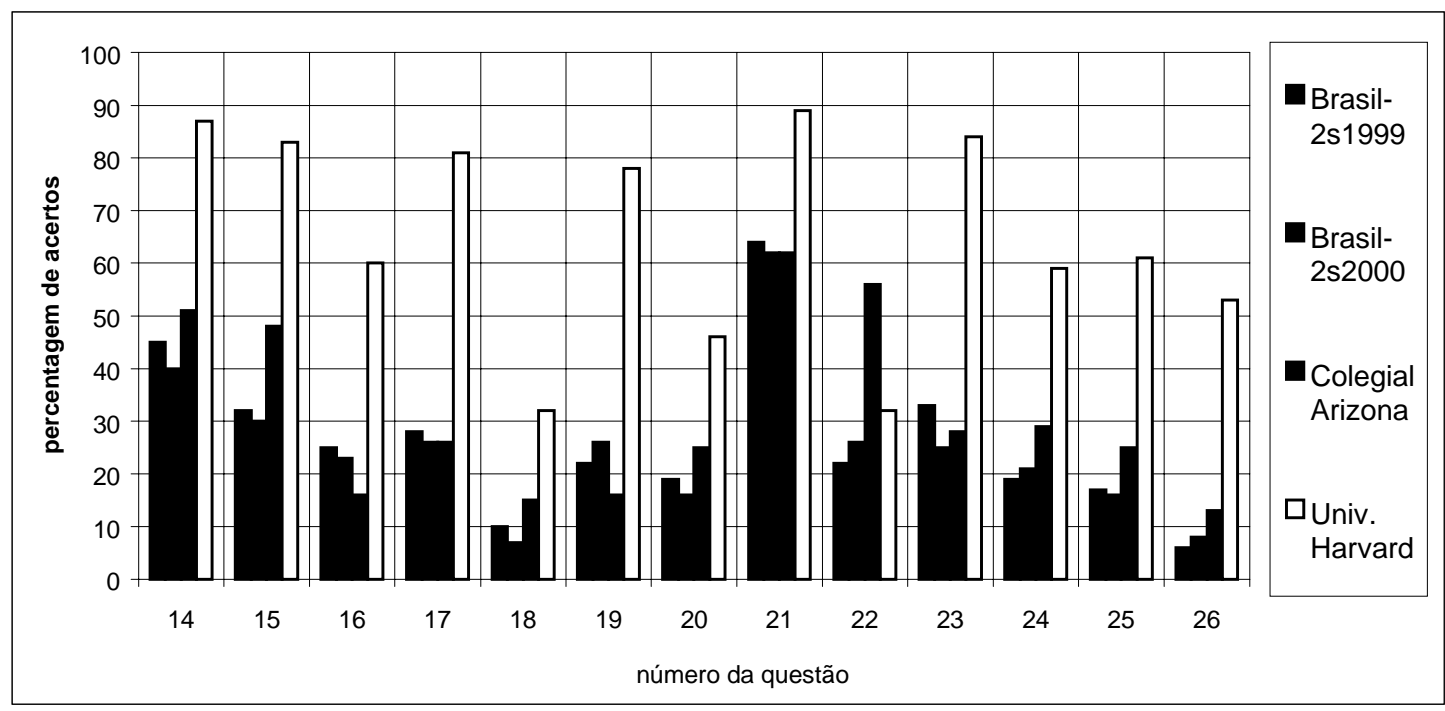

Figura 2. Resultados percentuais (questôes 14 a 26) obtidos na aplicação do Mechanics Baseline Test (agosto de 1999 e agosto de 2000), num colégio do Arizona e na Universidade de Harvard. 
Na última coluna da Tabela III, pode ser observado o escore z, calculado para a comparação entre as duas turmas brasileiras, para cada uma das questões do teste. Pode-se notar, pela análise desta tabela, que existe diferença significativa para um nível de significância de 0,05 , somente para as questões $1,6,9,11,14,18$ e 23 .

Como não se verificou diferença significativa no desempenho global das duas turmas analisadas, para simplificar a discussão e a análise dos resultados serão apresentados, a seguir, somente os percentuais relativos ao teste aplicado em agosto de 1999.

Fazendo-se uma análise global dos resultados, a média de acertos na parte de Cinemática, movimento linear, obtido através dos resultados das questões 1,2 , $3,18,23,24$ e 25 , foi de $28,7 \%$. Como se sabe, no ensino médio, essa parte tem merecido mais atenção da grande maioria dos professores. Portanto, esperava-se uma percentagem maior de acertos para esse tópico. $\mathrm{O}$ mesmo índice praticamente se repete para os outros tópicos, exceto para o caso de movimento curvilíneo, o qual teve uma média de acertos de cerca de $7 \%$, bem abaixo daquele observado para os outros casos.

É interessante observar que os maiores índices de respostas para a alternativa "f" ("Não sei responder") correspondem às questões 9, 11, 12 e 18. Para a solução dessas questões, além do conceito físico, era necessário o conhecimento de uma expressão matemática para o cálculo da grandeza pedida. Basicamente, o que se precisava saber para resolver tais questões eram expressões relativas à força de atrito, aceleração centrípeta, energia potencial e cinética, e a $2^{a}$ lei de Newton. Outras questões que necessitam de algum cálculo, também tiveram percentagens apreciáveis de respostas para a alternativa "f" $(13,14,17,23,24$ e 25). Nesse caso, necessitava-se do conhecimento das expressões da cinemática (velocidade média e aceleração média) e da $2^{a}$ lei de Newton, além da capacidade de interpretação gráfica.

Uma análise individual de algumas questões fornece alguns resultados também interessantes, conforme será detalhado a seguir.

As questões 1 e 2 tiveram índices de acerto relativamente altos. Na questão 1 , a resposta correta foi obtida por $60 \%$ dos alunos. Os $32 \%$ que escolheram a alternativa "a", provavelmente não fizeram um paralelo entre o espaçamento do diagrama apresentado no enunciado e as inclinações das retas do gráfico da velocidade, acertando apenas o formato geral da curva. Na questão 2 , houve $44 \%$ de acertos. Os $18 \%$ que optaram pela alternativa " $\mathrm{e}$ ", novamente acertaram o aspecto geral do gráfico, errando os valores dos coeficientes angulares obtidos a partir do gráfico da velocidade (questão 1).

Na questão 3 , que apenas $18 \%$ acertaram, a maioria das respostas (31\%) foi para a alternativa "d". Tem-se a impressão de que isso ocorreu devido ao estabelecimento de uma proporcionalidade entre força e velocidade, causada talvez por uma confusão entre os concei- tos de velocidade e de aceleração. Essa confusão entre tais conceitos tem sido observada há bastante tempo, constituindo um tipo de concepção espontânea apresentada por alunos de diferentes níveis [6, 7].

A questão 4, que obteve a maior percentagem de acertos em todo o teste, necessita do conceito de componente tangencial da aceleração. Essa foi a única questão em que os alunos brasileiros tiveram um índice melhor do que aquele observado em Harvard. Tem-se a impressão que os alunos responderam por "intuição" associando-se a direção da velocidade com a direção da aceleração, o que é válido para esta situação. Isso é reforçado pela análise da questão 5 , onde novamente a resposta mais selecionada foi aquela em que a direção da aceleração coincide com a da velocidade, o que não é válido para este caso. Como conseqüência, tivemos o menor índice de acertos para essa questão. Para a correta análise desse problema, é importante observar a mudança na trajetória do bloco e, portanto, notar que existe variação na direção da velocidade vetorial, o que leva à existência da componente normal da aceleração, fazendo com que as direções da velocidade e da aceleração não coincidam. O conceito de componente normal da aceleração está incluído novamente na questão 12, que teve também baixíssimo índice de acertos. Como já foi discutido, a média de acertos nas questões envolvendo movimento curvilíneo, como é o caso da questão 12, foi de apenas $7 \%$. Novamente a confusão entre os conceitos de velocidade e de aceleração pode ser observada pela pequena quantidade de acertos obtidos na questão 26. Essa questão envolve apenas o conhecimento de que em queda livre a aceleração é constante. A mistura entre os conceitos de velocidade e aceleração se torna aparente na medida em que a resposta mais freqüente foi a alternativa "d" (42\%), segundo a qual a aceleração de um objeto, após ser lançado verticalmente para cima, vai diminuindo até atingir o ponto de altura máxima, quando então passa a ter o valor zero. Esse é justamente o comportamento da velocidade.

Na questão 6, a maior percentagem de respostas foi para a alternativa "b", em que a direção da aceleração foi novamente tomada como sendo a mesma da velocidade. Assim como no caso da questão 26, a sua solução depende apenas do conhecimento do comportamento de um corpo em queda livre.

Na questão 7, a grande percentagem de respostas atribuídas à alternativa errada "d" $(66 \%)$ permite concluir que os conceitos de decomposição de força e de força resultante não estão presentes na grande maioria dos alunos. Aqui pode se observar um erro freqüente, em que se atribui sempre à força normal aplicada pelo plano no corpo, o mesmo valor da força peso do corpo.

Na questão 8 observa-se novamente a grande dificuldade dos alunos na análise de movimentos em curva e do entendimento do significado da aceleração normal. Para $47 \%$ dos alunos (que escolheram as alternativas 
"b" e "c"), se a velocidade é constante, a aceleração é zero, isto é, eles não levam em conta que a aceleração é resultado da mudança não só da intensidade do vetor velocidade, mas também de sua direção. Apenas $13 \%$ acertaram, sendo que $15 \%$ preferiram a alternativa "Não sei responder".

A questão 10, que se enquadra no tópico de energia, mostra que falta ao estudante o conhecimento da lei da conservação da energia mecânica, já que o índice de acerto foi de apenas $15 \%$. Uma grande parte das respostas $(63 \%)$ for para a alternativa "a", em que temos uma curvatura do escorregador que leva a uma "queda" mais brusca. Observe-se que apenas 2,3\% assinalaram "Não sei responder". Ainda neste tópico, temos a questão 20, sobre trabalho e energia cinética, que só obteve $19 \%$ de acertos. Uma boa percentagem, $37 \%$, escolheu a alternativa "b", parecendo que estabeleceram a proporção de que maior massa corresponde obrigatoriamente a maior energia cinética, esquecendose de que a velocidade também é determinante para a obtenção dessa grandeza. A questão 21 foi a segunda em maior percentagem de acertos do teste, $64 \%$, e admite solução seja por energia cinética, seja através da segunda lei de Newton. A solução talvez tenha sido feita também de forma intuitiva, imaginando-se que, para a mesma força, o corpo com a menor massa chega "mais rápido" ao destino.

Nas questões 13 e 14, com $21 \%$ e $45 \%$ de acertos, respectivamente, percebem-se falhas em relação à segunda lei de Newton. A questão 13, em que o elevador sobe com velocidade constante, parece ter criado no aluno mais dificuldades do que a 14 , em que o mesmo elevador está estacionário.

A questão 17 teve $28 \%$ de acertos, sendo que $51 \%$ escolheram como resposta a alternativa incorreta "c". Essa questão envolvia basicamente a aplicação da segunda lei de Newton, para dois sistemas com mesma força resultante e massas diferentes, para assim encontrar a relação de acelerações. A grande quantidade de respostas para a alternativa "c" denota um aparente descuido na leitura do enunciado, pois essa seria justamente a alternativa correta caso as massas fossem $m$ e $2 m$, quando o correto seria considerar $m$ e $3 m$.

A questão 18 envolve conhecimentos sobre aceleração (valor e sinal) e aplicação da segunda e da terceira lei de Newton, sendo que apenas $10 \%$ responderam corretamente. Interessante notar que as outras alternativas também tiveram aproximadamente essa percentagem de respostas, e $43 \%$ escolheram a alternativa "Não sei responder". Uma possibilidade para tal tipo de comportamento é que, embora conheçam a formulação da segunda (e da terceira) lei de Newton, os alunos têm dificuldades de aplicá-las quando a sua necessidade não está explícita no problema.

A questão 19 envolve o conhecimento sobre força re- sultante ou sobre princípio de superposição de forças. A maior percentagem dos alunos, $33 \%$, escolheu a direção da seta B como resposta. A direção correta é a da seta C, escolhida por $22 \%$ dos alunos.

Os tópicos Trabalho-Energia e Momento Linear (ou Quantidade de Movimento) comparecem com média de acertos de $26 \%$ e $32 \%$, respectivamente. Note-se que o índice de acertos para o conceito de momento linear foi relativamente alto, equivalente ao de cinemática. As percentagens de acertos de $32 \%$ (questão 15 ) e $25 \%$ (questão 16) chegam, portanto, a surpreender, uma vez que são solicitados conhecimentos de momento linear, de subtração de vetores e de impulso linear.

Já as respostas atribuídas à questão 22 indicam que o conceito de quantidade de movimento não é claro para a maioria, já que as alternativas "a", "b" e "c" tiveram praticamente as mesmas percentagens de respostas.

Um gráfico da velocidade versus tempo está no enunciado das questões 23, 24 e 25. A questão 23, sobre cálculo de aceleração média, obteve apenas $33 \%$ de acertos. Existe, aparentemente, um desconhecimento do significado gráfico da aceleração média (coeficiente angular da reta que liga os dois pontos). A questão 24, em que se pedia o cálculo do espaço percorrido entre dois instantes, obteve apenas $19 \%$ de respostas corretas. Talvez grande parte dos alunos não associe espaço percorrido com a área sob o gráfico fornecido ou tenha tido dificuldades em calcular essa área. Apenas $17 \%$ deles responderam corretamente à questão 25 , em que se pedia a velocidade média num intervalo de tempo. Nessa questão era necessário saber calcular o deslocamento através do gráfico da velocidade versus tempo, obtido na questão anterior, para então dividir este valor pelo intervalo de tempo. Boa parte daqueles que conseguiram resolver a questão 24 também conseguiram resolver a questão 25 .

\section{V.2. Comparação de amostras}

Uma outra análise interessante se refere à comparação do desempenho no teste aplicado no segundo semestre de 1999, entre calouros (418 alunos) e veteranos (76 alunos dependentes, ou seja, que foram reprovados pelo menos uma vez em Física I) do curso diurno. Calculando-se o porcentual médio de acertos para calouros e veteranos, obtém-se $25 \%$ e $27 \%$ respectivamente, com desvios-padrão de $11 \%$ e de $10 \%$. Calculando-se o escore reduzido, obtém-se $\mathrm{z}=-1,57$. Isso mostra que dentro de uma significância de 0,05 a diferença entre as médias de acertos de calouros e veteranos não é significativa. Pode-se notar visualmente pela Figura 3 que há muito pouca diferença entre as dificuldades enfrentadas por ambas categorias de alunos, sendo os percentuais de acerto bastante semelhantes. 


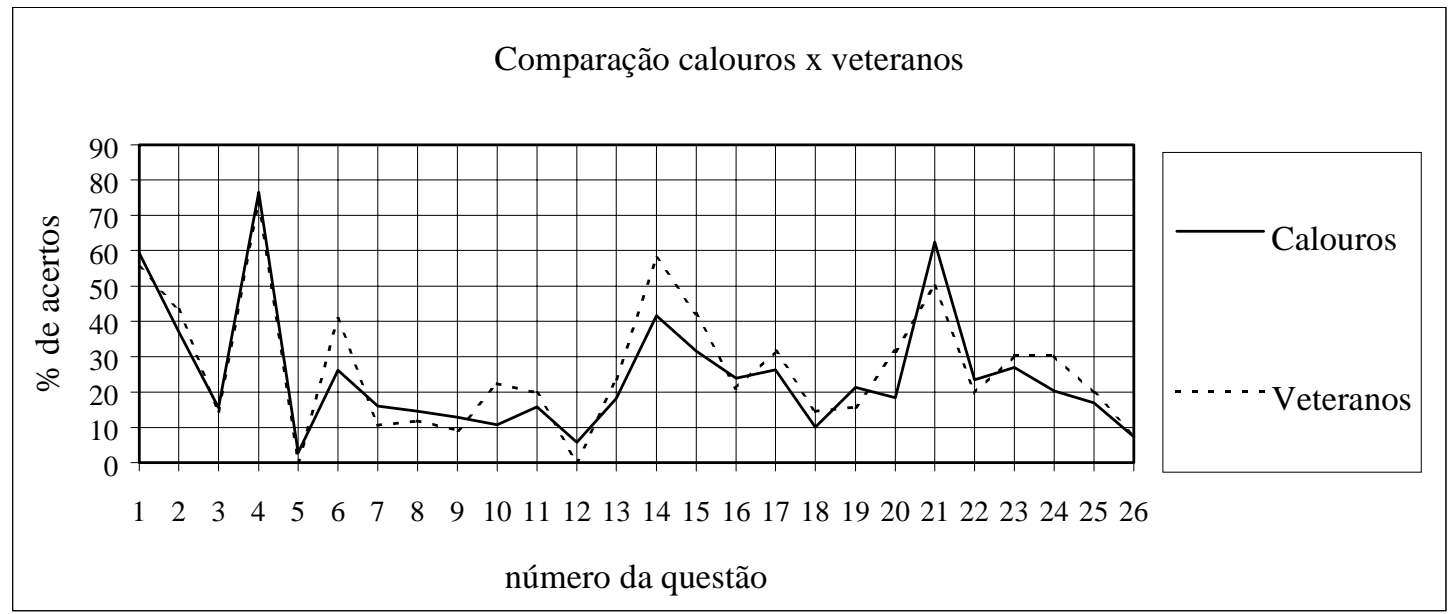

Figura 3. Gráfico comparativo do desempenho dos calouros (linha cheia) e veteranos (linha tracejada) do segundo semestre de 1999, no teste Mechanics Baseline Test.

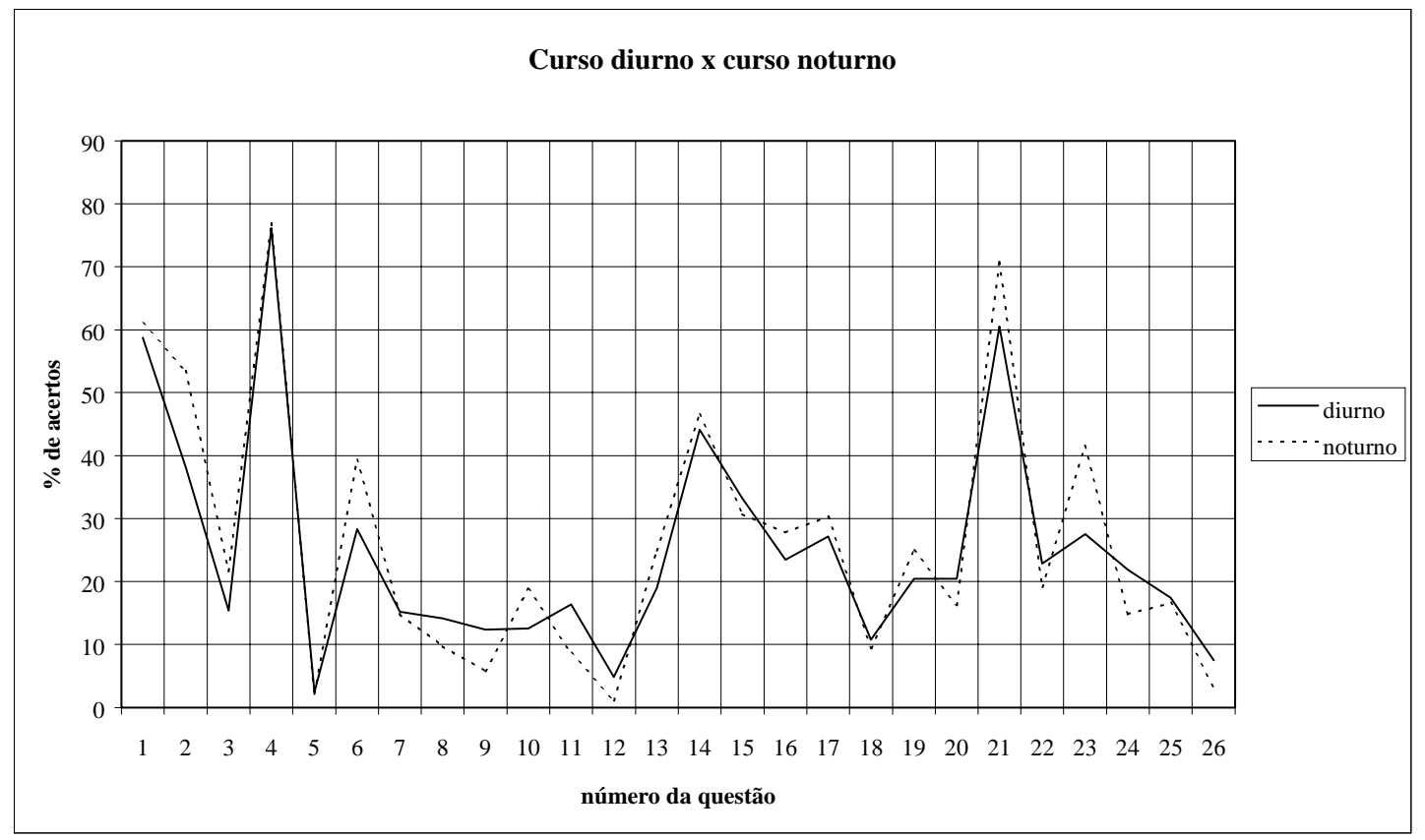

Figura 4. Percentagem de acertos obtida pelos alunos do curso de engenharia, período diurno e noturno, segundo semestre de 1999, no teste Mechanics Baseline Test.

A Figura 4 permite comparar o desempenho, no mesmo teste, dos alunos de Física I dos cursos diurno (494) e noturno (277), do segundo semestre de 1999. Calculando-se a média de acertos, obteremos $25 \%$ para o aluno do diurno e $27 \%$ para o aluno do noturno, ambos com desvio padrão de $11 \%$. Neste caso, $z=-2,42$, indicando que as diferenças são significativas para um nível de significância de 0,05 , porém não são significativas para um índice de significância de 0,01. Assim, existe provavelmente diferença significativa entre o desempenho das duas categorias de alunos, sendo os do noturno possivelmente um pouco mais bem preparados.
Isso poderia ser explicado pelo fato de o aluno do noturno cursar Física I no segundo período, tendo já tido a oportunidade de cursar um semestre de uma série de disciplinas de matemática.

\section{Considerações finais}

Tem-se observado, ao longo dos anos, uma gradual diminuição na capacidade de uso de ferramental matemático dos alunos que ingressam no curso superior. Vários demonstram dificuldades, por exemplo, em re- 
solver simples frações, na montagem e resolução de equações, em geometria e em trigonometria. Porém, não é somente a falta de ferramental matemático o grande obstáculo para um bom desenvolvimento desses alunos. Os resultados da aplicação do MBT confirmam a grande deficiência em relação aos conceitos básicos de física. A presença de concepções espontâneas que levam a uma visão restrita da natureza, parece ainda predominar na mente da maioria dos estudantes. A construção de algumas dessas concepções, por exemplo a proporcionalidade entre força e velocidade, se deve, em parte, ao fato de que diversos fenômenos que nos cercam necessitam da aplicação de forças para que as velocidades sejam mantidas, isto é, às vezes o movimento de objetos do dia-a-dia parece seguir melhor a descrição aristotélica do que a mecânica newtoniana. Isso tem sido reportado na literatura $[13,14,15]$, inclusive com a proposição de que se discuta as hipotéticas equações que descreveriam estes movimentos, para então se introduzir a mecânica newtoniana [13]. A confrontação entre as concepções apresentadas pelos alunos com aquelas aceitas cientificamente - mostrando-se que estas últimas explicam, de forma mais ampla, os fenômenos observados - parece ser uma forma importante de se atacar esse problema.

As deficiências apontadas anteriormente têm que ser enfrentadas pelos professores dos períodos iniciais, oferecendo, ao mesmo tempo, condições para que os estudantes possam ampliar seus conhecimentos, sua capacidade de raciocínio, e consolidar os conceitos fundamentais. Conhecer a forma de pensar dos alunos, trabalhar com as concepções espontâneas que trazem e planejar estratégias para reelaborá-las é, pois, de importância fundamental para que se possam minimizar as dificuldades conceituais apresentadas e assim maximizar o processo de aprendizagem.

\section{Agradecimentos}

Nossos agradecimentos aos professores Fábio do Prado, José Maria Bechara e Augusto Martins dos Santos pelo apoio, valiosas discussões e sugestões, e a todos os professores que colaboraram na aplicação do teste. Gostaríamos de agradecer também as importantes sugestões e comentários do árbitro, que nos chamou a atenção para uma série de pontos falhos e omissões presentes no texto original.

\section{Referências}

[1] Ver por exemplo o uso dessa técnica para o ensino de programação em

http://mathserv.monmouth.edu/coursenotes/kuntz/ Papers/topdown.htm, acessado em 13/03/2001.

[2] Um exemplo é o livro de Okuno, E., Caldas, I.L. e Chow, C., Física para ciências biológicas e biomédicas, Harbra, São Paulo (1982).

[3] Hewitt, P.G., Conceptual physics, Addison-Wesley, Massachusets, $8^{a}$ edição (1998).

[4] Beichner, R. J., Testing student interpretation of kinematics graphs, Am. J. Phys. 62, 750 (1994).

[5] Agrello, D.A. e Garg, R., Compreensão de gráficos de cinemática em física introdutória, Rev. Bras. Ens. Fís. 21 (1), 103 (1999).

[6] Zylbersztajn, A., Concepções espontâneas em física: exemplos em dinâmica e implicações para o ensino, Rev. Ens. Fís. 5 (2), 3 (1983).

[7] Villani, A., Pacca, J. L. A. e Hosoume, Y., Concepção espontânea sobre movimento, Rev. Ens. Fís. 7 (1), 37 (1985).

[8] Villani, A., Pacca, J. L. A., Kishinami, R. I., Hosoume, Y., Analisando o ensino de física: contribuições de pesquisas com enfoques diferentes, Rev. Ens. Fís. 4 (1), 23 (1982).

[9] Costa, S. S. C e Moreira, M. A., O papel da modelagem mental dos enunciados na resolução de problemas em física, Rev. Bras. Ens. Fís. 24 (1), 61 (2002).

[10] Hestenes, D. e Wells, M., Mechanics Baseline Test, The Phys. Teacher 30, 159 (1992).

[11] Hestenes, D., Wells, M. e Swackhamer, G., Force Concept Inventory., The Phys. Teacher 30, 141 (1992).

[12] Spiegel, M. R., Estatística, McGraw-Hill do Brasil, São Paulo (1974).

[13] Ed Disy, A. D. N. e Garner, J., Hypothetical preclassical equations of motion, The Phys. Teacher 37, 42 (1999).

[14] Waltham, C., Power requirements for rollerblading and bicycling, The Phys. Teacher 37, 379 (1999).

[15] Casper, B. M., Galileo and the fall of Aristotle: A case of historical injustice?, Am. J. Phys. 45, 325 (1977). 


\section{Anexo - Mechanics Baseline Test}

Obs.: Quando necessário, utilize aceleração da gravidade $\mathrm{g}=10 \mathrm{~m} / \mathrm{s}^{2}$

Considere o diagrama abaixo para responder às duas primeiras questões. O diagrama representa um objeto movendo-se ao longo de uma superfície horizontal. As posições indicadas no diagrama estão separadas por intervalos de tempo iguais. O primeiro ponto indica a posição em que o objeto começou a se mover e o último quando ele voltou a ficar em repouso.

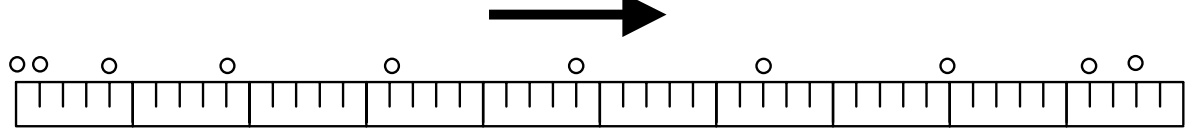

1.- Qual dos gráficos seguintes representa melhor a velocidade do objeto em função do tempo?

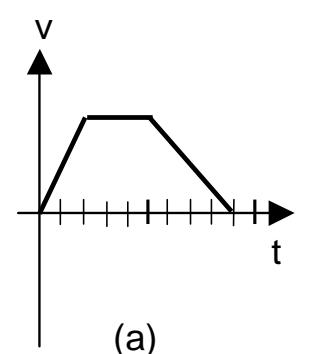

(a)

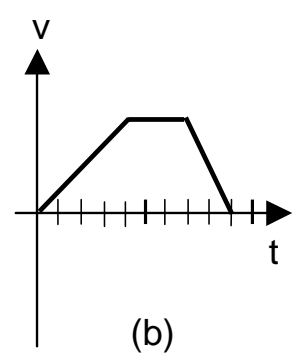

(b)

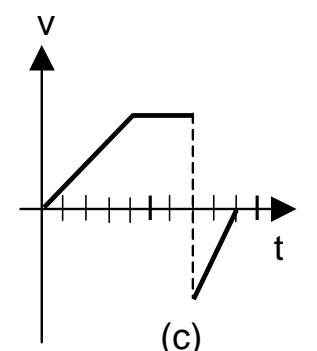

(c)

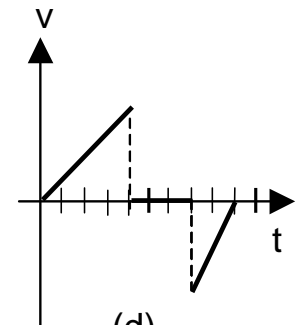

(d)

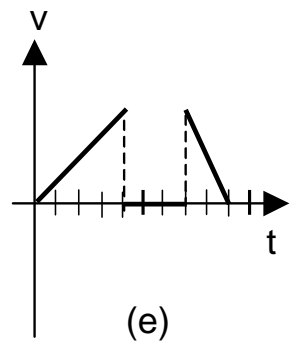

(e)

(f) Não sei responder

2.- Qual dos gráficos seguintes representa melhor a aceleração em função do tempo?

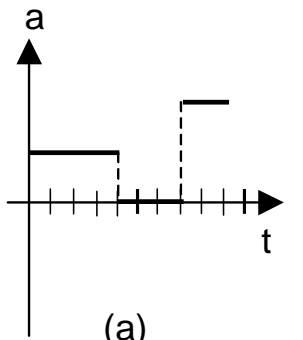

(a)

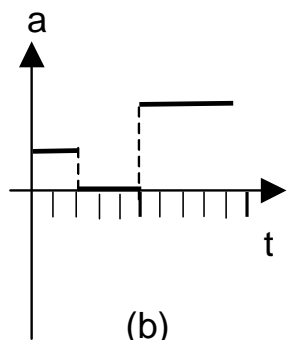

(b)

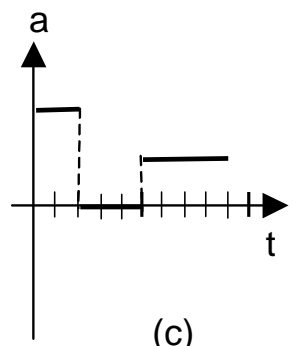

(c)

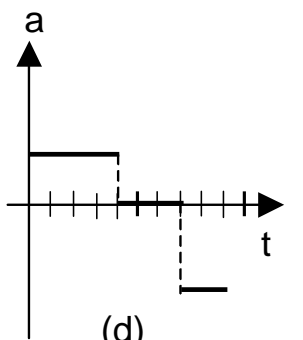

(d)

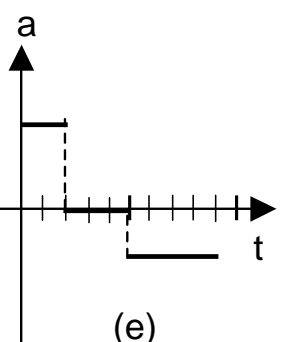

(e)

(f) Não sei responder

3.- No gráfico seguinte é mostrada a velocidade de um objeto em função do tempo.

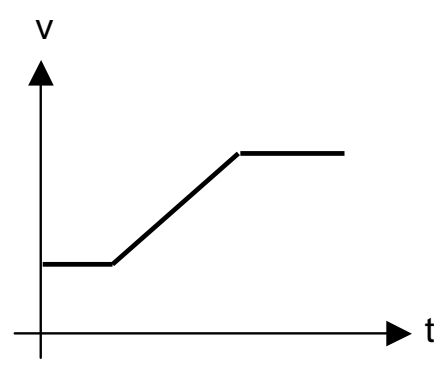


Qual dos gráficos abaixo mostra a relação entre a força resultante e o tempo?

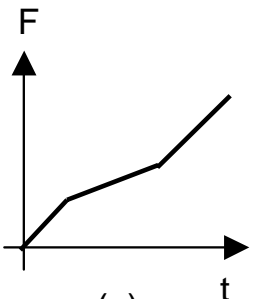

(a)

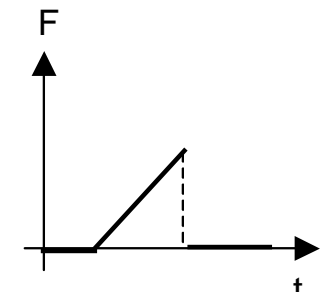

(b)

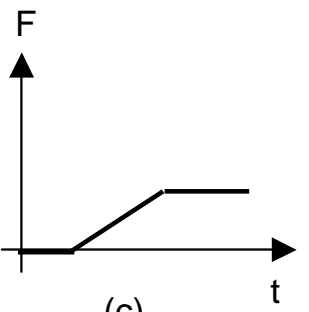

(c)

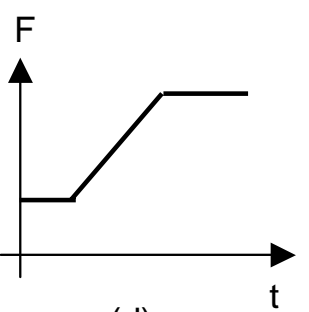

(d)

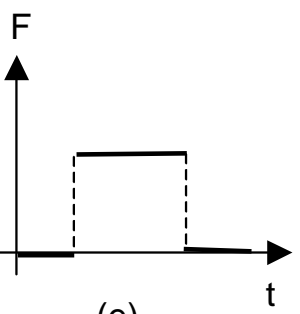

(e)

(f) Não sei responder

Baseie-se no gráfico abaixo para responder às três questões seguintes. Este diagrama representa um bloco deslizando ao longo de uma rampa sem atrito. As oito setas numeradas representam direções a serem tomadas como referência para responder às questões.

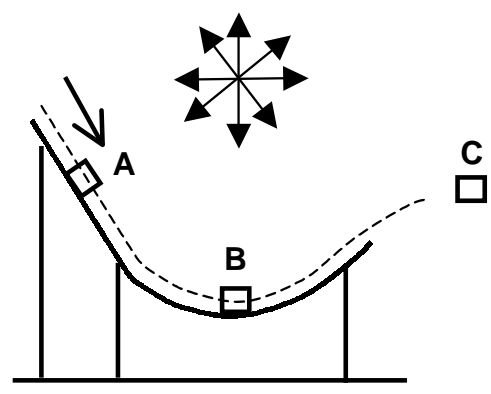

4.- A direção da aceleração do bloco, quando este estiver na posição $A$, é melhor representada

por qual das setas no diagrama?
(a) 1
(b) 2
(c) 4
(d) 5
(e) 6
( f) Não sei responder

5.- A direção da aceleração do bloco, quando este estiver na posição $B$, é melhor representada por qual das seguintes setas no diagrama?
(a) 1
(b) 3
(c) 5
(d) 7
(e) Nenhuma das setas, pois a aceleração é nula.
( f) Não sei responder

6.- A direção da aceleração do bloco (após deixar a rampa) na posição $C$, é melhor representada por qual das setas no diagrama?
(a) 1
(b) 3
(c) 5
(d) 6
(e) Nenhuma das setas, pois a aceleração é zero.
( f) Não sei responder 
7.- Uma pessoa empurra um bloco com velocidade constante através de uma superfície horizontal rugosa, aplicando uma força $F$. As setas no diagrama indicam corretamente as direções, mas não necessariamente as intensidades, das várias forças sobre o bloco. Qual das seguintes relações entre as intensidades das forças $\mathrm{W}, \mathrm{K}, \mathrm{N}$ e $\mathrm{F}$ deve ser verdadeira?

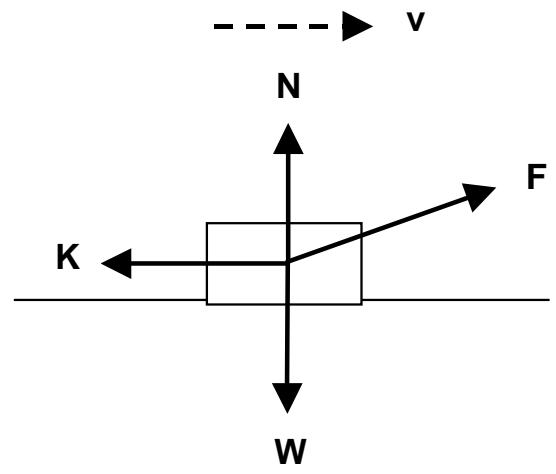

(a) $\mathrm{F}=\mathrm{K}$

(b) $\mathrm{F}=\mathrm{K}$ e N $>\mathrm{W}$

(c) $\mathrm{F}>\mathrm{K}$ e N $<\mathrm{W}$

(d) $\mathrm{F}>\mathrm{K}$ e N $=\mathrm{W}$

(e) Nenhuma das alternativas anteriores.

( f) Não sei responder

8.- Um pequeno cilindro metálico repousa sobre uma plataforma horizontal circular, a qual gira com velocidade constante como ilustrado no diagrama a seguir.

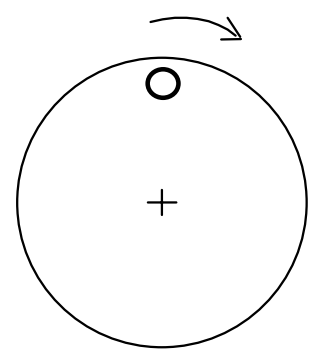

Qual dos seguintes conjuntos de vetores descreve melhor a velocidade, a aceleração e a força resultante agindo sobre o cilindro no ponto indicado no diagrama?

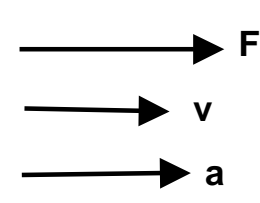

(a)

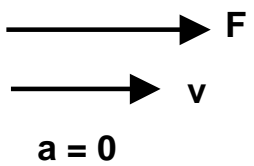

(b)

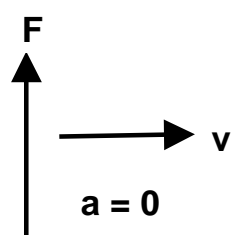

(c)

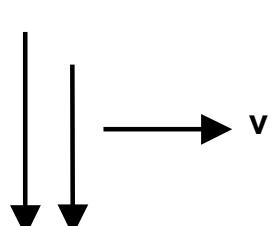

(d)

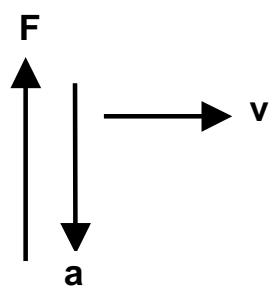

(e)

( f) Não sei responder

9.- Suponha que o cilindro metálico do problema anterior tenha massa de $0,10 \mathrm{~kg}$ e que 0 coeficiente de atrito estático entre a superfície e o cilindro seja 0,12. Se o cilindro está a 2,0 $\mathrm{m}$ do centro da plataforma, qual é aproximadamente a máxima velocidade com que o cilindro pode se mover ao longo de sua trajetória circular sem escorregar sobre a mesa? 

(a) 0
(b) está entre $0,5 \mathrm{~m} / \mathrm{s}$ e $1,0 \mathrm{~m} / \mathrm{s}$
(c) $1,0 \mathrm{~m} / \mathrm{s}$
(d) $1,5 \mathrm{~m} / \mathrm{s}$
(e) $2,0 \mathrm{~m} / \mathrm{s}$
(f) Não sei responder

10.- Uma garota deseja escolher um dos escorregadores, abaixo ilustrados, que lhe dê a maior velocidade possível quando atingir o final do escorregador. Desprezando o atrito, qual dos escorregadores ela deverá escolher?

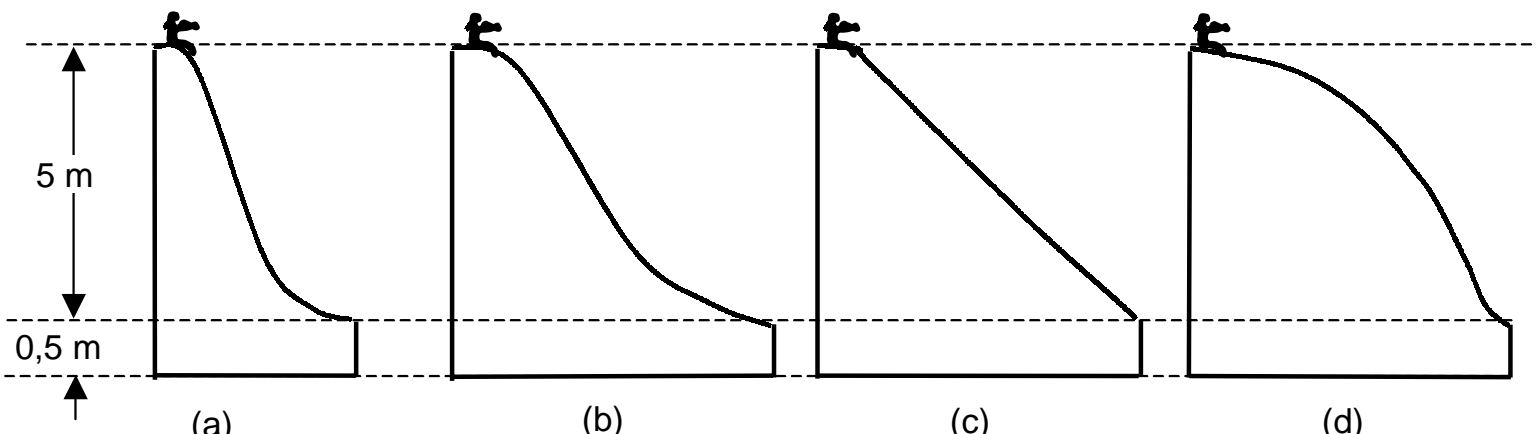

(a)

(b)

(c)

(d)

(e) Tanto faz, pois a velocidade será a mesma em qualquer um deles.

(f) Não sei responder

Consulte o diagrama a seguir para responder às duas questões seguintes: $X$ e $Z$ assinalam a mais alta e $Y$ a mais baixa posições de um menino de 50,0 kg que balança para a direita conforme indicado no diagrama.

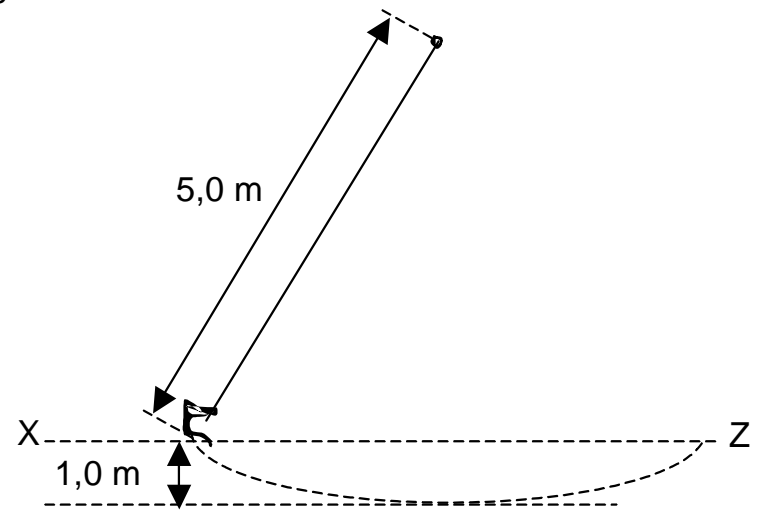

11.- Qual é aproximadamente a velocidade do garoto na posição $Y$ ?
(a) $2,5 \mathrm{~m} / \mathrm{s}$
(b) $4,5 \mathrm{~m} / \mathrm{s}$
(c) $20 \mathrm{~m} / \mathrm{s}$
(d) 0
(e) Nenhuma das anteriores.
(f) Não sei responder 
12. Qual é a força tensora no cabo na posição $Y$ ?
(a) $250 \mathrm{~N}$
(b) $525 \mathrm{~N}$
(c) $7 \times 10^{2} \mathrm{~N}$
(d) $1,1 \times 10^{3} \mathrm{~N}$
(e) Nenhuma das anteriores
( f) Não sei responder

Considere o diagrama a seguir para responder às duas questões seguintes.

Os blocos A e B, cada um com massa de $1,0 \mathrm{~kg}$ estão suspensos no teto de um elevador pelas cordas 1 e 2 .

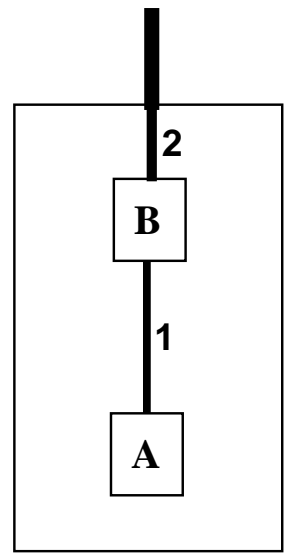

13. Qual é a força exercida pela corda 1 sobre o bloco $A$, quando o elevador está subindo com uma velocidade constante de $2,0 \mathrm{~m} / \mathrm{s}$ ?
(a) $2 \mathrm{~N}$
(b) $10 \mathrm{~N}$
(c) $12 \mathrm{~N}$
(d) $20 \mathrm{~N}$
(e) $22 \mathrm{~N}$
( f) Não sei responder

14. Qual é a força exercida pela corda 1 sobre o bloco B quando o elevador está estacionário?
(a) $2 \mathrm{~N}$
(b) $10 \mathrm{~N}$
(c) $12 \mathrm{~N}$
(d) $20 \mathrm{~N}$
(e) $22 \mathrm{~N}$
( f) Não sei responder

Basear-se no diagrama a seguir para responder às duas próximas questões.

O diagrama indica as trajetórias de duas bolas de aço, $\mathrm{P}$ e $\mathrm{Q}$, que colidem. 


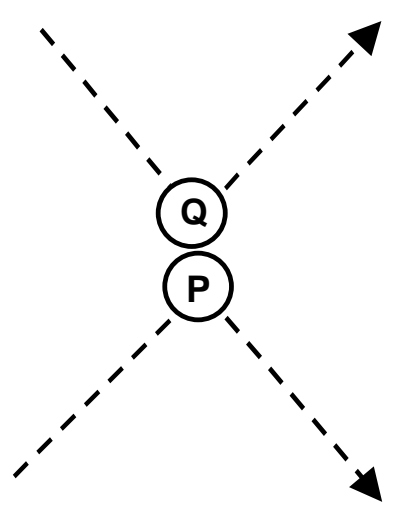

15. Qual das setas representa melhor a direção da variação do momento linear (quantidade de movimento) de cada bola?

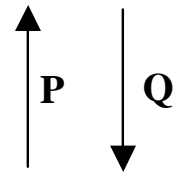

(a)

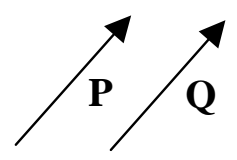

(b)

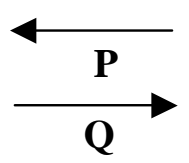

(c)

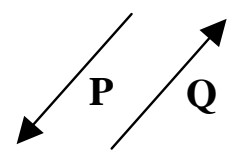

(d)

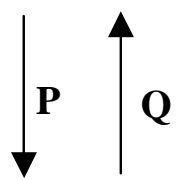

(e)

( f) Não sei responder

16. Qual das setas representa melhor a direção do impulso aplicado à bola $Q$ pela bola $P$ durante a colisão?

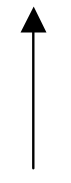

(a)

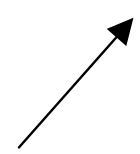

(b)

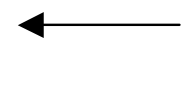

(c)

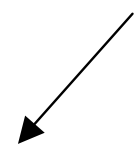

(d)

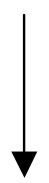

(e)

( f) Não sei responder

17. Um carro tem uma aceleração máxima de $3,0 \mathrm{~m} / \mathrm{s}^{2}$. Qual será sua máxima aceleração quando estiver rebocando um outro carro com o dobro de sua massa?
(a) $2,5 \mathrm{~m} / \mathrm{s}^{2}$
(b) $2,0 \mathrm{~m} / \mathrm{s}^{2}$
(c) $1,5 \mathrm{~m} / \mathrm{s}^{2}$
(d) $1,0 \mathrm{~m} / \mathrm{s}^{2}$
(e) $0,5 \mathrm{~m} / \mathrm{s}^{2}$
( f) Não sei responder

18. Uma mulher pesando $6,0 \times 10^{2} \mathrm{~N}$ está dentro de um elevador que sobe do primeiro para o sexto andar. Quando o elevador se aproxima do sexto andar, ele diminui sua velocidade de $8,0 \mathrm{~m} / \mathrm{s}$ para $2,0 \mathrm{~m} / \mathrm{s}$ em 3,0 s. Qual é a força média exercida pelo piso do elevador sobre a mulher durante este intervalo de tempo de 3,0 s? 

(a) $120 \mathrm{~N}$
(b) $480 \mathrm{~N}$
(c) $600 \mathrm{~N}$
(d) $720 \mathrm{~N}$
(e) $1200 \mathrm{~N}$
(f) Não sei responder

19. O diagrama a seguir representa um bloco que se move sobre uma superfície horizontal e sem atrito, no sentido indicado pela seta tracejada. Uma força constante $F$ (horizontal para a direita), mostrada no diagrama, está agindo sobre o bloco. Para que o objeto fique sujeito a uma força resultante na direção da seta tracejada, em qual das direções indicadas por $A, B$, C, D, E, deverá estar agindo uma outra força?
(a) (A)
(b) (B)
(c) (C)
(d) (D)
(e) $(\mathrm{E})$
(f) Não sei responder

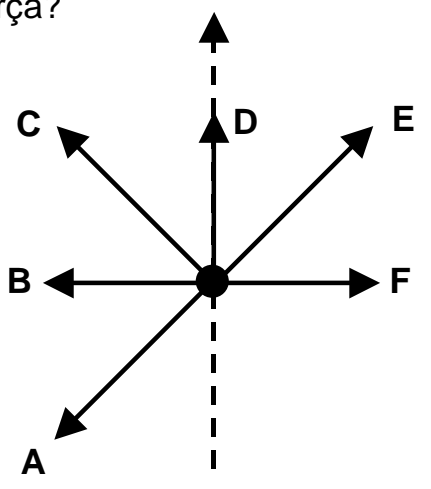

Refira-se ao diagrama seguinte para responder às próximas três questões.

O diagrama representa dois objetos sobre uma mesa horizontal sem atrito. O bloco B tem massa quatro vezes maior que o bloco $A$. Os dois blocos são empurrados, a partir do repouso, por duas forças iguais.

20. Qual dos blocos terá maior energia cinética ao atingir a linha de chegada?

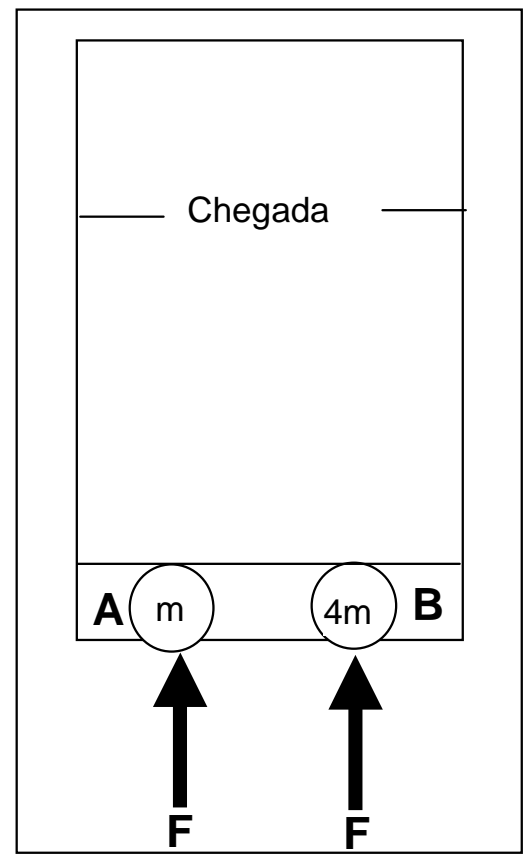
(a) O bloco $\mathrm{A}$
(b) O bloco B
(c) Ambos os blocos terão a mesma energia cinética
(d) Faltam informações para determinar
(e) Não é possível determinar
( f) Não sei responder 
21. Qual dos blocos alcança primeiro a linha de chegada?
(a) O bloco $\mathrm{A}$
(b) O bloco B
(c) Os blocos chegarão juntos
(d) Faltam informações para determinar
(e) Não é possível determinar
( f) Não sei responder

22. Qual dos blocos terá maior quantidade de movimento ao alcançar a linha de chegada?
(a) O bloco $\mathrm{A}$
(b) O bloco B
(c) Os blocos terão a mesma quantidade de movimento
(d) Faltam informações para determinar
(e) Não é possível determinar
( f) Não sei responder

Para responder às próximas três questões, baseie-se no gráfico da velocidade em função do tempo mostrado a seguir, que representa o movimento de um objeto em uma dimensão.

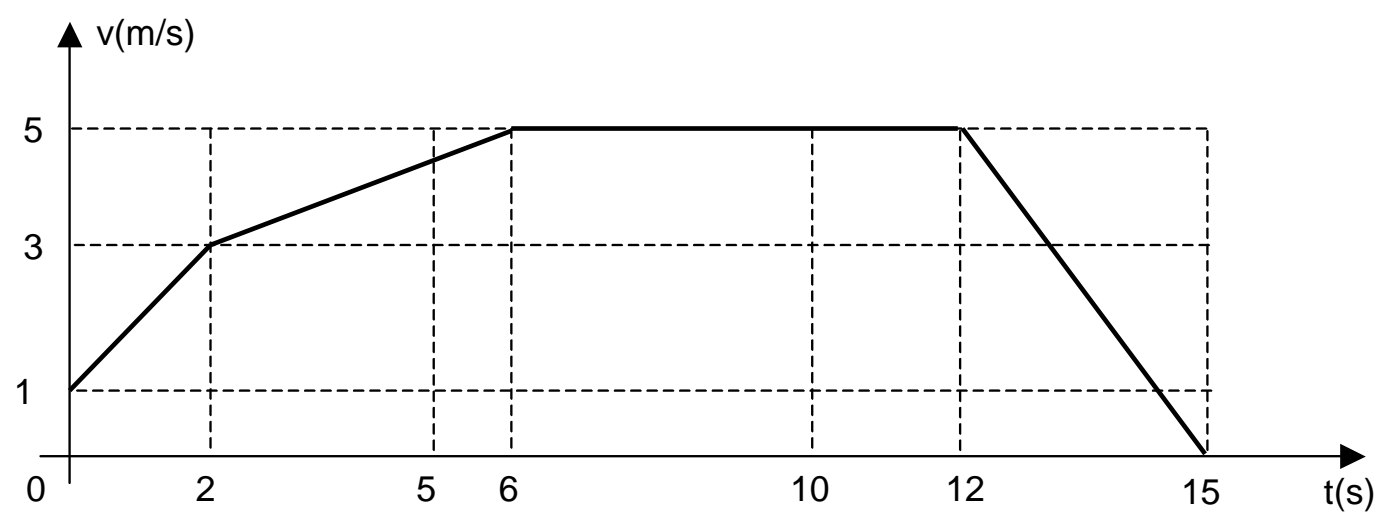

23. Qual é aproximadamente a aceleração média do objeto entre $t=0 \mathrm{~s}$ e $t=6,0 \mathrm{~s}$ ?
(a) $3,0 \mathrm{~m} / \mathrm{s}^{2}$
(b) $1,5 \mathrm{~m} / \mathrm{s}^{2}$
(c) $0,83 \mathrm{~m} / \mathrm{s}^{2}$
(d) $0,67 \mathrm{~m} / \mathrm{s}^{2}$
(e) Nenhuma das anteriores.
( f) Não sei responder

24. Qual o espaço percorrido pelo objeto entre $t=0$ e $t=6,0 \mathrm{~s}$ ?
(a) $20 \mathrm{~m}$
(b) $8,0 \mathrm{~m}$
(c) $6,0 \mathrm{~m}$
(d) $1,5 \mathrm{~m}$
(e) Nenhuma das anteriores.
( f) Não sei responder 
25. Qual é aproximadamente a velocidade média do objeto nos primeiros 6,0 s?
(a) $3,3 \mathrm{~m} / \mathrm{s}$
(b) $3,0 \mathrm{~m} / \mathrm{s}$
(c) $1,8 \mathrm{~m} / \mathrm{s}$
(d) $1,3 \mathrm{~m} / \mathrm{s}$
(e) Nenhuma das anteriores.
( f) Não sei responder

Refira-se ao diagrama abaixo para responder a questão seguinte.

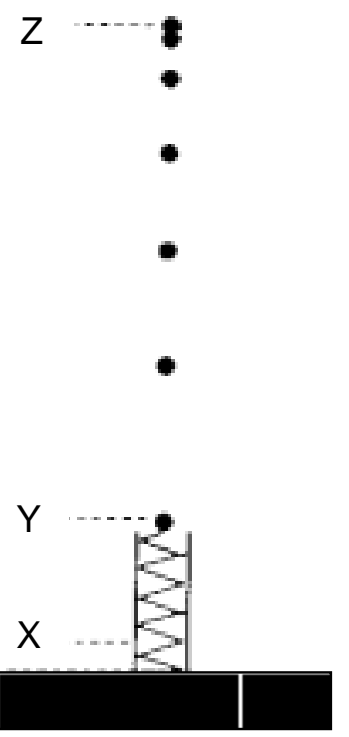

A figura representa uma fotografia múltipla de uma bolinha sendo atirada verticalmente para cima. A mola, com a bolinha em cima, foi comprimida até o ponto marcado com $X$ e então foi solta. A bola deixou a mola no ponto marcado $\operatorname{com} \mathrm{Y}$, e atingiu a altura máxima no ponto marcado com Z.

26. Assumindo que a resistência do ar é desprezível, podemos afirmar que:

(a) A maior aceleração da bola foi no momento em que atingiu o ponto $Y$ (ainda em contato com a mola).

(b) A aceleração da bola foi decrescendo em seu trajeto do ponto $Y$ ao ponto $Z$.

(c) A aceleração da bola foi zero no ponto $Z$.

(d) Todas as respostas acima estão corretas.

(e) A aceleração da bola foi a mesma em todos os pontos de sua trajetória, do ponto $\mathrm{Y}$ ao $\mathrm{Z}$.

( f) Não sei responder 